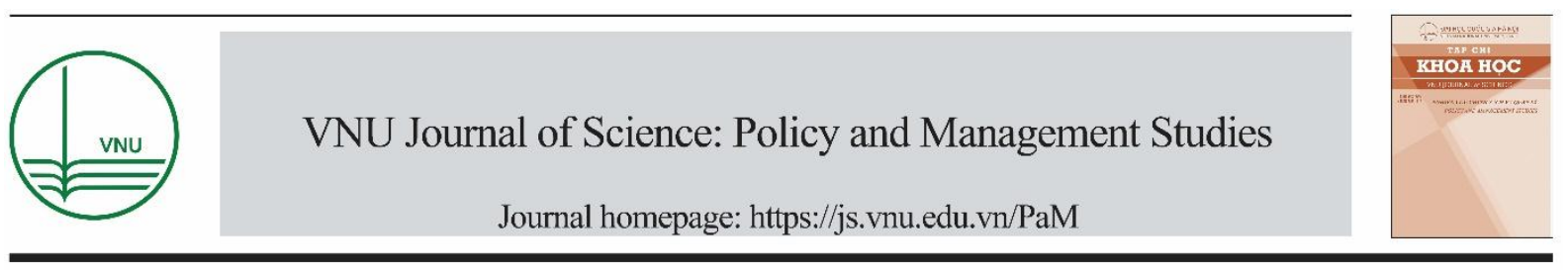

Review Article

\title{
The Process of Sustainable Development and the Linkage to the Social - Ecological Transformation in the World and in Vietnam
}

\author{
Vo Thanh Son* \\ VNU-Central Institute of Natural Resources and Environmental Studies (VNU-CRES), \\ 19 Le Thanh Tong, Hanoi, Vietnam \\ Received 11 January 2021 \\ Revised 27 January 2021; Accepted 27 January 2021
}

\begin{abstract}
Sustainable development is a global trend to build a prosperous society, especially to promote green growth towards ecological approach and based on sustainable use of natural resources in the context of climate change. This article, therefore, is an attempt to synthesize the sustainable development process in the world, from the initial awareness of the role of the environment in the development process in the 1980s, to the development of Agenda 21 in the 1990s, to develop and implement the 2030 agenda for sustainable development in the present time. The change in awareness and practice of sustainable development also demonstrates the trend of social-ecological transformation as a development trend and is an urgent requirement towards building a prosperous and sustainable society. Integrating sustainable development into international and national development policies can be considered as a form of promoting social-ecological transformation. The UNESCO' system of Biosphere Reserves as a model for promoting sustainable development initiatives towards harmony between people and nature can be considered as a model of a socialecological system. Vietnam as a country actively participating the sustainable development process in the world has made great efforts to build a prosperous and sustainable society.
\end{abstract}

Keywords: Sustainable development, social - ecological transformation, Vietnam.

\footnotetext{
*Corresponding author.

Email address: vtson@cres.edu.vn
}

https://doi.org/10.25073/2588-1116/vnupam.4293 


\title{
Tiến trình phát triển bền vững và sự gắn kết tới quá trình chuyển đổi sinh thái - xã hội trên thế giới và ở Việt Nam
}

\author{
Võ Thanh Sơn* \\ Viện Tài nguyên và Môi trường, Đại học Quốc gia Hà Nội, \\ 19 Lê Thánh Tông, Hà Nội, Việt Nam \\ Nhận ngày 11 tháng 01 năm 2021 \\ Chỉnh sửa ngày 27 tháng 01 năm 2021; Chấp nhận đăng ngày 27 tháng 01 năm 2021
}

\begin{abstract}
Tóm tắt: Phát triển bền vững là xu thế toàn cầu nhằm xây dựng được một xã hội phồn thịnh, đặc biệt là thúc đẩy tăng trưởng xanh theo hướng sinh thái gắn với sử dụng bền vững tài nguyên thiên nhiên trong bối cảnh biến đổi khí hậu. Bài viết này, vì thế, là một nổ lực tổng hợp tiến trình PTBV trên thế giới, từ nhận thức ban đầu về vai trò của môi trường trong quá trình phát triển trong những thập niên 1980s tới việc xây dựng chương trình nghị sự 21 trong thập kỷ 1990s, tới việc xây dựng và thực hiện chương trình nghị sự 2030 vì sự PTBV trong thời gian hiện tại. Sự thay đổi nhận thức và thực tiễn PTBV cũng thể hiện xu thế chuyển đổi sinh thái - xã hội như là một xu thế phát triển và là một yêu cầu cấp bách nhằm hướng tới xây dựng một xã hội thịnh vượng và bền vững. Tích hợp PTBV vào các chính sách phát triển quốc tế cũng như quốc gia có thể được coi như là một hình thức thúc đẩy quá trình chuyển đổi sinh thái - xã hội. Hệ thống các Khu dự trữ sinh quyển của UNESCO như là một mô hình thúc đẩy thực hiện các sáng kiến về PTBV theo hướng hài hòa giữa con người và thiên nhiên có thể được coi như là một hình mẫu của một hệ sinh thái - xã hội. Việt Nam là một quốc gia tích cực tham gia vào tiến trình $\mathrm{PTBV}$ trên thế giới và có nhiều nỗ lực nhằm xây dựng một xã hội hội thịnh vượng và bền vững.
\end{abstract}

Tù khóa: Phát triển bền vững, chuyển đổi sinh thái - xã hội, Việt Nam.

\section{Mở đầu}

Cuối thế kỷ thứ 20 và đầu thế kỷ thứ 21 , thế giới chứng kiến những chuyển biến to lớn, đặc biệt tiến trình nhận thức và thúc đẩy phát triển bền vững $(\mathrm{PTBV})$ ở quy mô toàn cầu cũng như quy mô quốc gia. Liên hợp quốc luôn giữ một vai trò then chốt trong tiến trình này, từ nâng cao nhận thức về môi trường vào thập niên $60^{\prime}$, tới xây dựng chiến lược môi trường trong thập niên $80^{\prime}$, tới ý tưởng về kết hợp giữa môi trường và phát triển những năm 90 ' và cuối cùng thúc đẩy quá trình PTBV vào đầu thế kỷ 21. Biến đổi khí hậu là một thách thức mang tính toàn cầu và có tác động mạnh mẽ tiến trình này. Tăng trưởng xanh cũng là một xu thế PTBV về mặt kinh tế trong bối cảnh biến đổi khí hậu khi mà khía cạnh sản xuất và tiêu dùng xanh gắn với sử dụng hiệu quả tài nguyên thiên nhiên và giảm phát thải khí nhà kính ngày càng trở thành một xu thế phát triển tất yếu của thế giới. Trong đó, xây dựng một xã hội bền vững và thịnh vượng với bản chất là hài hòa giữa con người và thiên nhiên ngày càng trở nên rõ nét. Vì thế, dường như Hệ sinh thái-xã hội (Social-Ecological System) đang được hình thành và quá trình Chuyển đổi sinh

\footnotetext{
*Tác giả liên hệ.

Địa chi email: vtson@cres.edu.vn

https://doi.org/10.25073/2588-1116/vnupam.4293
} 
thái-xã hội (Social-Ecological Transformation) cũng đang được định hình.

Trong bối cảnh đó, bài báo này là một nỗ lực nhằm tổng hợp tiến trình $\mathrm{PTBV}$ trên thế giới và ở Việt Nam, và qua đó gắn với nhận thức về hệ sinh thái-xã hội và chuyển đổi sinh thái-xã hội đang hình thành ở Việt Nam.

\section{Tiến trình phát triển bền vững và xu thế chuyển đổi sinh thái ở trên thế giới}

Tiến trình $\mathrm{PTBV}$ gắn chặt với khái niệm và nhận thức về PTBV, mà theo đó sự nhận thức về PTBV trên thế giới trong hơn nửa thế kỷ qua có thể chia thành các giai đoạn i) Trước năm 1990; ii) Từ 1990-2000; iii) Từ 2000 cho đến nay.

\subsection{Giai đoạn truớc 1990: Nhận thức về môi trường trong quá trình phát triển}

Thế kỷ 20 phải đối mặt với những thách thức to lớn về kinh tế-xã hội-môi trường và sự phát triển, bao gồm: i) Sự phân hóa giàu nghèo và mất ổn định chính trị; ii) Sự nghèo đói cùng cực; iii) Suy dinh dưỡng; iv) Bệnh tật; v) Tăng dân số; vi) Sử dụng năng lượng toàn cầu; vii) Biến đổi khí hậu; viii) Suy thoái tài nguyên (nước, đất); ix) Mất và suy thoái đa dạng sinh học; $x$ ) Ô nhiễm; xi) Các vấn đề đô thị; xii) Sự tương tác giữa các vấn đề trên. Vì vậy, Chương trình Nghị sự 21 toàn cầu đã nhấn mạnh: "Loài người đang đứng trước một thời điểm quyết định của lịch sử. Thế giới phải đương đầu với tình trạng ngày càng xấu đi của sự nghèo khó, đói kém, bệnh tật, thất học và sự suy thoái không ngừng của hệ sinh thái. Sự cách biệt giữa người giàu và người nghèo đang tăng lên" [1].

Qua các thời kỳ khác nhau, khái niệm về PTBV thể hiện khát vọng của loài người trong sự nghiệp xây dựng một xã hội phồn vinh và cuộc sống bền vững. Thuật ngữ "phát triển bền vững" xuất hiện lần đầu tiên vào năm 1980 trong ấn phẩm Chiến lược Bảo tồn Thế giới [2] với nội dung rất đơn giản: "Sự phát triển của nhân loại không thể chỉ chú trọng tới phát triển kinh tế mà còn phải tôn trọng những nhu cầu tất yếu của xã hội và sự tác động đến môi trường sinh thái học".
Tuy nhiên, khái niệm được đưa ra trong Báo cáo "Tương lai chung của chúng ta" của Ủy ban Thế giới về Môi trường và Phát triển của Liên hợp quốc là thông dụng và có tính khái quát nhất, như sau: "Phát triển bền vững là sự phát triển nhằm đáp ứng các nhu cầu hiện tại mà không làm tổn hại đến khả năng đáp ứng các nhu cầu của các thế hệ tương lai" [3].

Như vậy, nhận thức của sự phát triển xuất phát từ thông điệp "Những giới hạn của sự tăng trưởng" (The limits of Growth) hoặc Không tăng trưởng (Crossance zero) của Câu lạc bộ Rome [4] chủ yếu liên quan tới giới hạn của tài nguyên thiên nhiên và môi trường so với sự phát triển kinh tế của thế giới. Tiếp theo sau, sự thành lập Chương trình Con người và Sinh quyển (Man and Biosphere Program) của tổ chức UNESCO vào năm 1971 với mục tiêu là phát triển cơ sở khoa học cho việc sử dụng hợp lý và bảo tồn các tài nguyên của sinh quyển và cải thiện quan hệ toàn cầu giữa con người và thiên nhiên, môi trường. Chiến lược bảo tồn thế giới [2] đã khẳng định tầm quan trọng của bảo tồn thiên nhiên và bảo vệ môi trường trong quá trình phát triển. Tiếp theo, Chiến lược bảo tồn thế giới, các tổ chức IUCN, UNEP và WWF đã cụ thể hóa với những khuyến nghị về cải cách luật pháp, thể chế và quản trị nhằm thúc đẩy quá trình phát triển theo hướng bền vững, đặc biệt trong mối quan hệ giữa bảo tồn và phát triển [5]. Khái niệm về PTBV [3] đã khẳng định sự phát triển phải gắn với việc sử dụng hợp lý tài nguyên thiên nhiên nhằm đáp ứng nhu cầu của hiện tại và tương lai.

Sự thay đổi nhận thức về phát triển như trên đã phản ánh xu thế phát triển thế giới dựa trên khai thác sử dụng tài nguyên thiên nhiên tới sự phát triển gắn kết bảo tồn thiên nhiên như là quá trình bước đầu trong chuyển đổi sinh thái - xã hội (social-ecological transformation).

\subsection{Tù 1990-2000: Xây dưng Chuơng trình Nghi} sụ 21 về sự phát triển bền vũng

Khái niệm về PTBV sau đó ngày càng được hoàn thiện theo tiến trình thực hiện phát triển trên thế giới. 
Liên hợp quốc thành lập Hội đồng PTBV vào năm 1992, sau đó được thay bằng Diễn đàn Chính trị Cấp cao HLDF (High Level Political Forum - HLPF) tại Hội nghị của Liên hợp quốc về $\mathrm{PTBV}$ tại Rio de Janeiro từ năm 2012 và là tổ chức của LHQ chịu trách nhiệm trong việc thúc đẩy tiến trình PTBV trên thế giới. Liên hợp quốc đã tổ chức các Hội nghi thượng đỉnh thảo luận về xu hướng phát triển bền vững trên thế giới và thúc đẩy tiến trình trên thế giới trong 10 năm một, vào các năm 1992, 2002 và 2012. Trong mồi hội nghị, các nhà lãnh đạo của các quốc gia thường thông qua các thỏa thuận chính trị và cam kết thực hiện tại mỗi quốc gia.

Hội nghị về Môi trường và Phát triển tổ chức tại Rio de Janeiro năm 1992 tiếp tục phát triển những ý tưởng liên hệ các vấn đề môi trường với vấn đề phát triển. Với việc thông qua Chương trình nghị sự 21 về PTBV tại Hội nghị, đến nay, hàng trăm quốc gia trên thế giới đã xây dựng Chương trình nghị sự 21 quốc gia, làm cơ sở cho chiến lược $\mathrm{PTBV}$ cho từng nước.

Như vậy, giai đoạn này vấn đề môi trường đã được đặt ngang hàng với vấn đề phát triển khi LHQ tổ chức Hội nghị RIO 1992 với việc phê duyệt CTNS 21 và một số công ước về ĐDSH và BĐKH. Đây thực sự là một thông điệp mạnh mẽ khi việc hài hòa giữa bảo vệ môi trường / bảo tồn thiên nhiên và phát triển kinh tế xã hội đã trở thành chiến lược cho định hướng PTBV trên thế giới.

\subsection{Tù 2000 cho đến nay: Thực hiện muc tiêu thiên niên kỷ MDG và muc tiêu phát triển bền vũng $S D G$}

Hội nghị Thượng đỉnh về PTBV tổ chức tại Johannesburg năm 2002 (Rio + 10) với Chương trình "Thực hiện Kế hoạch Hành động Johannesburg" đã khẳng định thực hiện các mục tiêu mà Hội nghị Rio năm 1992 thông qua phát triển dựa trên ba trụ cột - kinh tế, xã hội và môi trường. Mười năm sau đó, Hội nghị Thượng đỉnh về PTBV tại Rio de Janeiro (Rio + 20) vào năm 2012 đã nhấn mạnh đến xu hướng PTBV liên quan đến nền kinh tế xanh. Hơn nữa, nội dung của PTBV đã được xem xét trong bối cảnh mới khi vấn đề biến đổi khí hậu đang ngày càng trở thành một thách thức cho toàn thể nhân loại.

Năm 2001, Liên Hợp Quốc thông qua 8 Mục tiêu Phát triển Thiên niên kỷ (MDGs) cho giai đoạn 2000-2015, tập trung vào các khía cạnh xóa đói, giảm nghèo, thúc đẩy y tế, giáo dục đồng thời gắn chặt với công tác bảo vệ môi trường. Cũng trong giai đoạn này, Báo cáo đánh giá hệ sinh thái thiên niên kỷ [6] có vai trò quan trọng trong thay đổi nhận thức của thế giới khi coi con người là một hợp phần của thiên nhiên, và việc đánh giá hệ sinh thái đều được xem xét các hoạt động của con người, mà đặc biệt là đã chú ý tới tác động tương hỗ giữa hệ tự nhiên và hệ xã hội. Khái niệm dịch vụ hệ sinh thái như là những lợi ích của con người từ thiên nhiên và đa dạng sinh học đã được đưa ra trong báo cáo này (Xem Hình 1 và 2$)$.

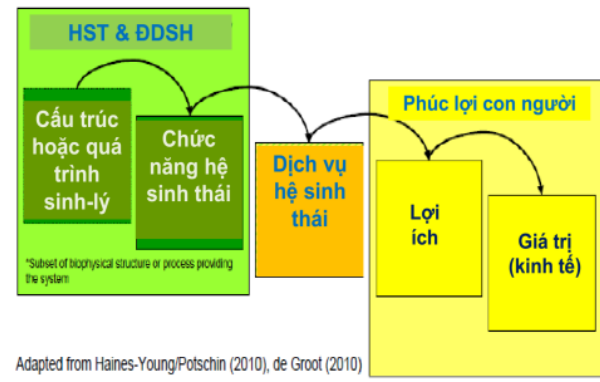

Hình 1. Mối quan hệ của hệ sinh thái, dịch vụ hệ sinh thái và phúc lợi của con người

Năm 2015 là thời điểm khi Liên Hợp Quốc đều đánh giá kết quả thực hiện các Mục tiêu Phát triển Thiên niên kỷ (MDG) trên toàn thế giới và đề xuất 17 Mục tiêu Phát triển bền vững (SDGs) và 169 mục tiêu cụ thể cho mười lăm năm tiếp theo 2016-2030, và được áp dụng cho tất cả các nước trên thế giới, bao gồm cả các nước phát triển và đang phát triển [7]. Các mục tiêu PTBV bao gồm tất cả các khía cạnh của $\mathrm{PTBV}$, liên quan tới i). Xoá đói giảm nghèo, ii). An ninh lương thực, iii) Sức khỏe và hạnh phúc, iv). Chất lượng giáo dục, v). Bình đẳng giới, vi). Nước sạch và vệ sinh môi trường, vii). Năng lượng, viii). Việc làm bền vững và tăng trưởng kinh tế, ix). Công nghiệp, đổi mới và cơ sở hạ tầng; $x$ ). 
Giảm bất bình đẳng; xi). Thành phố và cộng đồng bền vững, xii). Tiêu thụ và có trách nhiệm sản xuất, xiii). Hành động khí hậu, xiv). Cuộc sống dưới nước, $\mathrm{xv}$ ). Cuộc sống trên mặt đất, xvi). Hòa bình, công bằng và thể chế mạnh, xvii).
Quan hệ đối tác vì mục tiêu PTBV. Đây là một nền tảng quan trọng cho mỗi quốc gia trên thế giới thông qua các mục tiêu PTBV phù hợp với bối cảnh của mình.

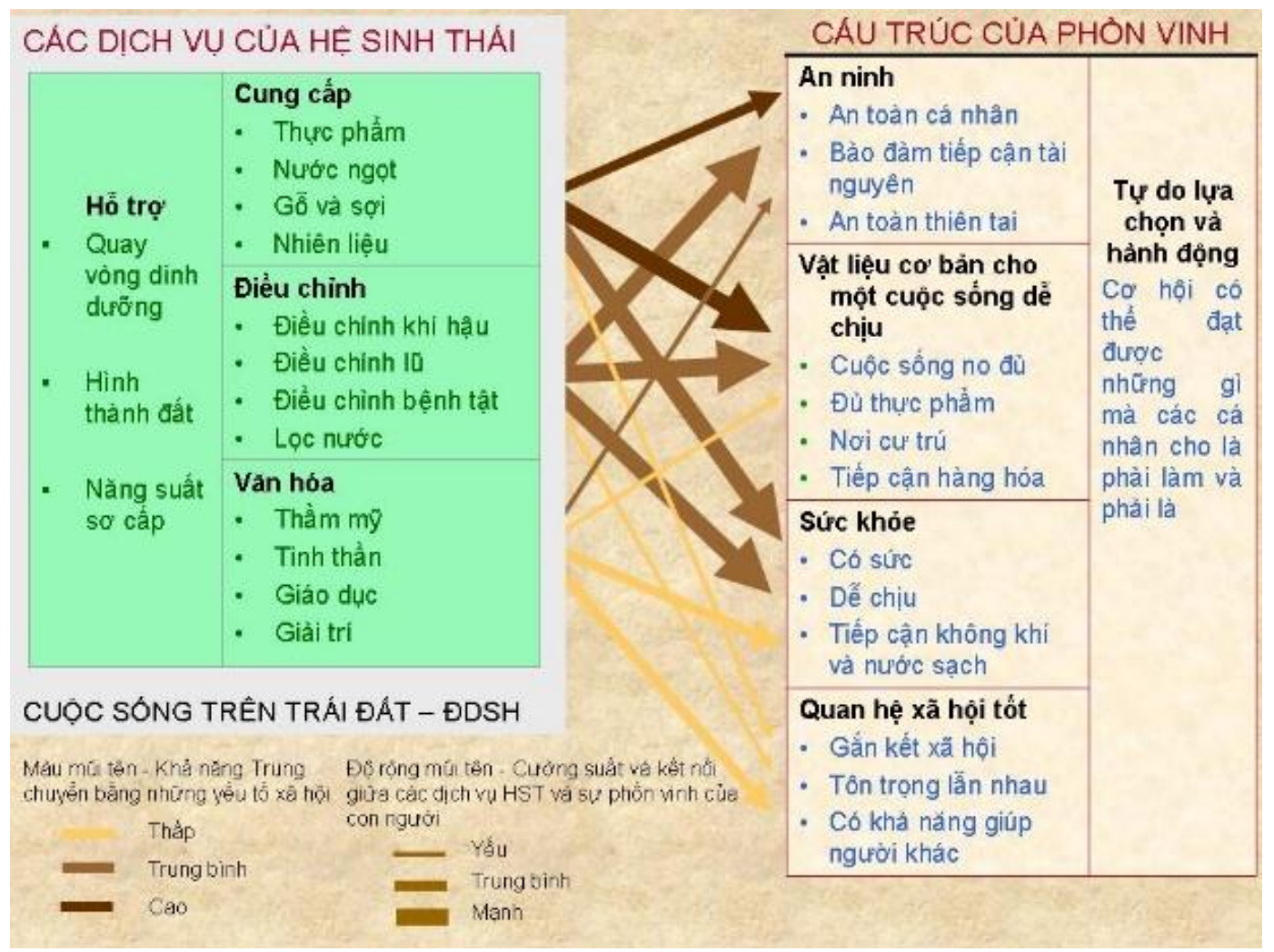

Hình 2. Mối quan hệ giữa dịch vụ hệ sinh thái và sự thịnh vượng của con người

Khái niệm PTBV, vì thế, ngày càng được cụ thể hóa theo các tiến trình nêu trên. Cụ thể, PTBV là sự phát triển hài hòa cả về 3 mặt: Kinh tế - Xã hội - Môi trường để đáp ứng những nhu cầu về đời sống vật chất, văn hoá, tinh thần của thế hệ hiện tại nhưng không làm tổn hại, gây trở ngại đến khả năng cung cấp tài nguyên để phát triển kinh tế - xã hội mai sau, không làm giảm chất lượng cuộc sống của các thế hệ trong tương lai (Xem hình 3). Hay nói một cách khác: muốn phát triển bền vững thì phải cùng đồng thời thực hiện 3 mục tiêu: (1) Phát triển hiệu quả về kinh tế; (2) Phát triển hài hòa các mặt xã hội; nâng cao mức sống của các tầng lớp dân cư và (3) Cải thiện môi trường, bảo đảm phát triển

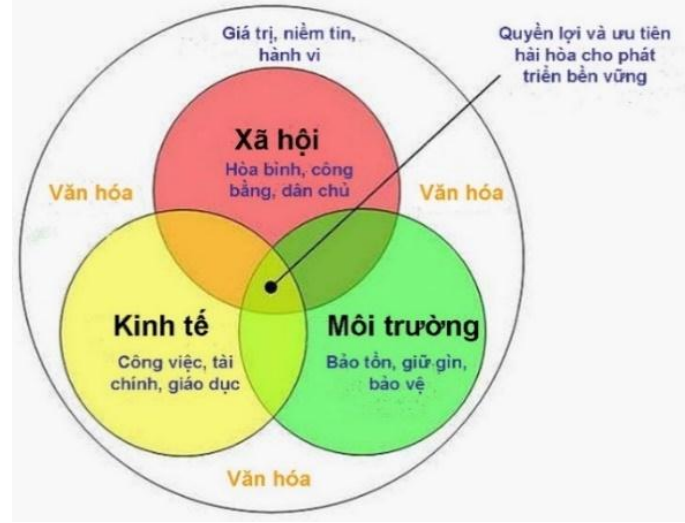

Hình 3. Phát triển bền vững theo 3 trụ cột kinh tế-xã hội-môi trường 
theo Chương trình nghị sự 2030 [8], PTBV được gắn với 5 chữ "P" trong tiếng Anh. Cụ thể Phát triển bền vững là sự phát triển vì "Con người" (People), là sự phát triển trong nguồn lực của "Trái đất" (Planet), là sự phát triển nhằm đạt được "Sự thịnh vượng" (Prosperity), là sự phát triển được thực hiện trong môi trường "Hòa bình" (Peace), là sự phát triển thực hiện bằng giải pháp "Hợp tác/Đối tác" (Partnership) (Xem hình 4).

Như vậy, tiến trình thực xây dựng và thực hiện phát triển bền vững trên thế giới có thể được tóm tắt trong Bảng 1 dưới đây.

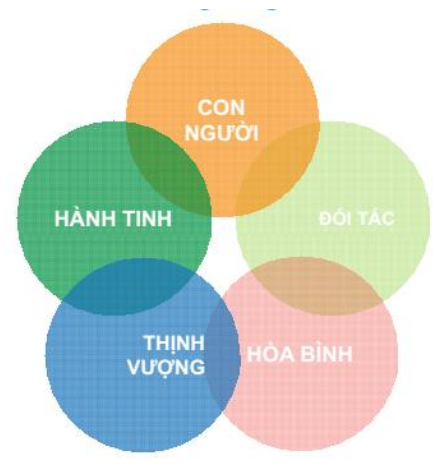

Hình 4. Phát triển bền vững dựa theo 5 khía cạnh theo 5 chữ "P" bằng tiếng Anh

Bảng 1. Tiến trình và nhận thức về PTBV trên thế giới

\begin{tabular}{|c|c|}
\hline Tiến trình PTBV & Đặc điểm \\
\hline 1963: Sách Mùa xuân câm lặng & Thay đồi nhận thức về MT, đặc biệt về DDT \\
\hline 1968: Câu lạc bộ Rome & $\begin{array}{l}\text { Báo cáo giới hạn của sự tăng trưởng kinh tế, đặc biệt phụ thuộc } \\
\text { vào tài nguyên thiên nhiên có hạn }\end{array}$ \\
\hline $\begin{array}{l}\text { 1970: Chương trình Con người và Sinh quyển } \\
\text { hình thành (MAB) }\end{array}$ & $\begin{array}{l}\text { Cơ sở khoa học cho sự sử dụng hợp lý và bảo tồn TNTN của } \\
\text { sinh quyển }\end{array}$ \\
\hline 6/1972: Hội nghị MAB & Hội nghị của LHQ đầu tiên về con người và sinh quyển \\
\hline $\begin{array}{l}\text { 1980: Chiến lược bảo tổn thế giới được xây } \\
\text { dựng }\end{array}$ & "Chiến lược bảo tồn quốc tế" (UNEP, IUCN, WWF) \\
\hline \multicolumn{2}{|l|}{ 1984: Thành lập UB MT\&PT (Brundland) } \\
\hline $\begin{array}{l}\text { 1987: Báo cáo của HĐ MT\&PT “Tương lai } \\
\text { chung của chúng ta" }\end{array}$ & $\begin{array}{l}\text { Báo cáo đầu tiên về phát triển bền vững, trong đó khái niệm } \\
\text { tồng quát được đưa ra }\end{array}$ \\
\hline 1992: Hội nghị thượng đỉnh LHQ & Thế giới thông qua CTNS 21 (Agenda 21) \\
\hline 2002: Hội nghị thượng đỉnh PTBV & Kế hoạch hành động về phát triển bền vững \\
\hline 2000: Liên Hợp quốc & Mục tiêu PT thiên niên kỷ (MDG) \\
\hline $\begin{array}{l}\text { 2012: Hội nghị thượng định về PTBV Rio+20 } \\
\text { của Liên Hợp quốc }\end{array}$ & $\begin{array}{l}\text { Hội nghị đánh giá kết quả đạt được sau } 20 \text { năm thực hiện } \\
\text { chương trình nghị sự } 21\end{array}$ \\
\hline $\begin{array}{l}\text { 2015: Diễn đàn chính trị cấp cao của Liên hợp } \\
\text { quốc }\end{array}$ & $\begin{array}{l}\text { Thông qua } 17 \text { mục tiêu PTBV (SDG) và } 165 \text { mục tiêu cụ thể } \\
\text { (Targets) }\end{array}$ \\
\hline
\end{tabular}

Trong những thập niên vừa qua, Chuyển đổi sinh thái - xã hội (Socio-Ecological Transformation - SET) là một xu thế và là một yêu cầu cấp bách đặt ra trong quá trình xây dựng một xã hội bền vững khi mà trên thực tế phương thức sản xuất chủ yếu trên thế giới, đặc biệt là tư bản chủ nghĩa và lối sống mà nó gây ra là không bền vững, cả về mặt xã hội hay sinh thái [9]. Sự chuyển đồi bao gồm những thay đổi về thể chế, kinh tế - xã hội và quản lý môi trường nhằm xây dựng được một xã hội thân thiện với môi trường, và sự phát triển hài hòa với thiên nhiên. Tiến trình phát triển bền vững trong nửa thế kỷ 20 và đầu thế kỷ 21 cũng phản ánh xu thế này với mục đích xây dựng được một xã hội bền vững. Điều này đã được khẳng định trong văn kiện của Liên hợp quốc về Chương trình Nghị sự 2030 với tiêu đề "Chuyển đổi thế giới của chúng ta: Chương trình nghị sự 2030 vì sự phát triển bền vững” [8]. 


\section{Tích hợp phát triển bền vững vào kế hoạch phát triển quốc gia như là một hình thức thúc đẩy quá trình chuyển đổi sinh thái - xã hội}

\subsection{Tích hợp phát triển bền vũng vào chính sách toàn cầu của Liên hợp quốc trên thế giới}

\subsubsection{Bản chất của việc tích hợp}

Bảng 2. Bản chất và đặc điểm của việc tích hợp trong các chương trình nghị sự về thiên nhiên/môi trường và phát triển

\begin{tabular}{|c|c|c|c|}
\hline $\begin{array}{l}\text { Mức } \\
\text { độ } \\
\text { tích } \\
\text { hợp }\end{array}$ & $\begin{array}{l}\text { Chương } \\
\text { trình nghị } \\
\text { sự về thiên } \\
\text { nhiên, môi } \\
\text { trường } \\
\text { (Chương } \\
\text { trình xem } \\
\text { xét khía } \\
\text { cạnh phát } \\
\text { triển như } \\
\text { thế nào?) }\end{array}$ & $\begin{array}{l}\text { Bản chất } \\
\text { của việc } \\
\text { tích hợp }\end{array}$ & $\begin{array}{l}\text { Chương } \\
\text { trình nghị } \\
\text { sự về phát } \\
\text { triền } \\
\text { (Chương } \\
\text { trình xem } \\
\text { xét khía } \\
\text { cạnh thiên } \\
\text { nhiên, môi } \\
\text { trường như } \\
\text { thế nào?) }\end{array}$ \\
\hline $\mathrm{Cao}$ & $\begin{array}{l}\text { 4. Thiên } \\
\text { nhiên cùng } \\
\text { với phát } \\
\text { triển }\end{array}$ & $\begin{array}{l}\text { 4. Tính bền } \\
\text { vững và } \\
\text { công bằng }\end{array}$ & $\begin{array}{ll}4 . & \text { Phát } \\
\text { triển cùng } \\
\text { với thiên } \\
\text { nhiên }\end{array}$ \\
\hline $\begin{array}{l}\text { Trung } \\
\text { bình }\end{array}$ & $\begin{array}{l}\text { 3. Thiên } \\
\text { nhiên cho } \\
\text { con người }\end{array}$ & $\begin{array}{l}\text { 3. Hiệp } \\
\text { lực/đồng } \\
\text { vận }\end{array}$ & $\begin{array}{l}3 . \quad \text { Môi } \\
\text { trường } \\
\text { cùng hưởng } \\
\text { lợi với phát } \\
\text { triển }\end{array}$ \\
\hline Thấp & $\begin{array}{lr}2 . & \text { Thiên } \\
\text { nhiên bỏ } \\
\text { qua người } \\
\text { dân }\end{array}$ & 2. An toàn & $\begin{array}{l}2 . \\
\text { triển } \\
\text { "không làm } \\
\text { hại" tới } \\
\text { thiên nhiên }\end{array}$ \\
\hline $\begin{array}{l}\text { Không } \\
\text { có }\end{array}$ & $\begin{array}{l}\text { 1. Thiên } \\
\text { nhiên } \\
\text { không có } \\
\text { người dân }\end{array}$ & 1. Riêng rẽ & $\begin{array}{l}\text { 1. Phát } \\
\text { triển bằng } \\
\text { cách } \\
\text { chuyển đổi } \\
\text { thiên nhiên }\end{array}$ \\
\hline
\end{tabular}

Nguồn: Theo Bass, 2015: Hình 1, tr. 5 [10].

Hội nghị quốc tế của Liên Hợp Quốc do UNDESA/UNEP/UNDP tổ chức về Phương pháp tích hợp PTBV trong hoạch định chính sách môi trường và phát triển [10] đã nhấn mạnh bản chất của việc tích hợp là đi từ hoạt động riêng rẽ, tới hoạt động hợp tác (hợp lực) và cuối cùng là tính bền vững (xem Bảng 2). Chương trình nghị sự về thiên nhiên, môi trường đi từ triết lý "bảo tồn vị bảo tồn", tức là bảo tồn tách rời với con người, để cuối cùng tiến tới triết lý "bảo tồn vị nhân sinh", tức là thiên nhiên hòa đồng với sự phát triển. Trong chiều ngược lại, chương trình nghị sự về phát triển đi từ chuyển đổi, khai thác thiên nhiên cho sự phát triển để cuối cùng tiến đến sự phát triển hài hòa với thiên nhiên (cùng thắng - win-win). Như vậy, mức độ tích hợp đi từ "không có tích hợp" cho đến "tích hợp cao".

Tích hợp chính sách là một quá trình đưa ra quyết định chiến lược và hành chính để đạt được một mục tiêu nào đó và quá trình thực hiện đòi hỏi các hành động tích hợp của chính phủ [11]. Công cụ tích hợp bao gồm công cụ định tính, như xây dựng các kịch bản khác nhau cho quá trình hoạch định chính sách PTBV và công cụ định lượng, như phân tích dựa theo thông số đầu vàođầu ra [12, tr.13-22].

\subsubsection{Cấp độ và cách thức tích hơp}

Tích hợp chính sách là một quá trình, chứ không phải chỉ là kết quả, không chỉ đơn thuần là tập hợp các chính sách gắn kết với nhau (coherent policies), không chỉ là phép cộng của điều phối (coordination) và kết nối chính sách (policy coherence). Tích hợp chính sách là một quá trình đưa ra quyết định chiến lược và hành chính để đạt được một mục tiêu nào đó, không chỉ bao gồm cả giai đoạn thiết kế và quá trình thực hiện đòi hỏi các hành động tích hợp của chính phủ [11]. Sự tích hợp chính sách, không chỉ tích hợp theo chiều ngang giữa các bộ ngành, mà còn theo chiều dọc theo các cấp độ khác nhau của chính phủ và thậm chí theo đường chéo giữa các bộ ngành và các cấp khác nhau [13].

Tổ chức các nước Hợp tác kinh tế và phát triển $(\mathrm{OECD})$ đã xây dựng được Hướng dẫn kỹ thuật đánh giá tính bền vững trong các chính sách phát triển quốc gia khi xem xét PTBV như là một thể thống nhất, bao gồm 3 chiều cạnh KTXH-MT và áp dụng trong Đánh giá tác động bền vững (sustainability impact assessment - SIA) [14]. Sau đó, Hội đồng Kinh tế và Xã hội (ESCAP) của Liên Hợp Quốc đã xây dựng được 
khuôn khổ và công cụ để tích hợp 3 chiều cạnh KT-XH-MT của PTBV cho chính sách phát triển quốc gia và thường phải dựa theo quy trình hoạch định chính sách (policy cycle), theo cách tư duy hệ thống, đồng thời hiểu rõ và áp dụng khái niệm đánh đổi [12, tr.7-12]. Công cụ tích hợp bao gồm công cụ định tính, như xây dựng các kịch bản khác nhau cho quá trình hoạch định chính sách PTBV và công cụ định lượng, như phân tích dựa theo thông số đầu vào-đầu ra $[12$, tr.13-22].

\subsubsection{Một số mô hình phát triển bền vũng}

Một số mô hình đã được đề xuất, chẳng hạn như khái niệm về PTBV dựa trên ba trụ cột kinh tế-xã hội-môi trường [10], hoặc đánh giá sự tương tác giữa các hệ thống tự nhiên và hệ thống xã hội bằng cách xem xét các dịch vụ hệ sinh thái vì lợi ích của con người [6], hoặc đánh giá sinh kế bền vững thông qua xem xét 5 nguồn vốn được DFID (1999) đề xuất [15]. Ý tưởng cốt lõi của tích hợp tính bền vững là những ý tưởng về 3 trụ cột, kinh tế, xã hội và môi trường, do đó, các chương trình IUCN 2005 - 2008, được thông qua vào năm 2005, sử dụng các mô hình vòng tròn lồng vào nhau để chứng minh rằng ba mục tiêu cần phải được tích hợp tốt hơn, với hành động để khắc phục tình trạng cân bằng giữa kích thước của PTBV [16].

Để thúc đẩy và thực hiện PTBV, một số học giả đã tiếp tục cải thiện các mô hình hiện có. Một ví dụ là khái niệm "Ranh giới hành tinh" hay là hệ thống hỗ trợ sự sống của hành tinh được Rockstrom và cs [17-18] đưa ra nhằm xác định một khoảng không gian hoạt động an toàn cho nhân loại, như là một tiền đề cho PTBV. Những ranh giới này bao gồm: i) Biến đổi khí hậu; ii). Tốc độ thất thoái đa dạng sinh học; iii) Can thiệp vào chu trình phốt pho và nitơ toàn cầu; iv) Suy kiệt ôzôn tầng bình lưu; v) A xít hóa đại dương; vi) Sử dụng nước ngọt toàn cầu; vii) Thay đổi hệ thống đất đai; viii) Tải lượng sol khí của khí quyển; ix) Ô nhiễm hóa học. Tuy nhiên, do sự phát triển mạnh mẽ của con người, ít nhất 3 giới hạn của ranh giới này đã bị vượt qua, đó là mức độ thất thoát đa dạng sinh học, biến đổi khí hậu và tác động của con người lên chu trình ni-tơ [19]. Mô hình này có thể được sử dụng để xem xét những giới hạn của trái đất trong định hướng chiến lược phát triển của thế giới. Khái niệm này đã được các nhà hoạch định chính sách của các nước trên thế giới rất quan tâm, bao gồm cả tổ chức của Liên hợp quốc, cũng như các tổ chức phát triển [20] và một số nước châu Âu thử nghiệm áp dụng.

Một ví dụ khác là mô hình Doughtnut do tổ chức Oxfam đề xuất nhằm cụ thể hóa những hợp phần của PTBV [21] nhằm biểu diễn một chiều cạnh (dimention) xã hội của các "Ranh giới hành tinh" (Planetary boundaries) trong khi nhấn mạnh tình trạng đói nghèo và bất công bằng toàn cầu và đề xuất một không gian công bằng và an toàn cho con người. Mô hình "Doughnut" có ba thành phần chính: lĩnh vực, các chỉ số và các ngưỡng: i). Các lĩnh vực là những khối kiến thức rộng lớn, cần phải tìm hiểu, nghiên cứu: ví dụ như, thất thoát đa dạng sinh học và thay đổi sử dụng đất trong phạm vi ranh giới của hành tinh, và thu nhập, thực phẩm, thức ăn và nơi trú ẩn đầy đủ trong mặt bằng xã hội; ii). Các chỉ số trong một số lĩnh vực đã được chọn để đo lường tình trạng hiện tại.

Gần đây nhất, mô hình $\mathrm{PTBV}$ gắn với 17 mục tiêu PTBV (SDG) được phát triển dựa trên 3 hợp phần, với hợp phần quan trong nhất là sinh quyển - nơi có các cấu trúc và chức năng của hệ sinh thái - bao quanh hợp phần về xã hội, và vùng lõi là các hoạt động kinh tế (Xem hình 5). Đây cũng có thể được xem như là một mô hình thực hiện phát triển bền vững trong khuôn khổ thực hiện Chương trình nghị sự phát triển bền vững từ nay đến năm 2030 .

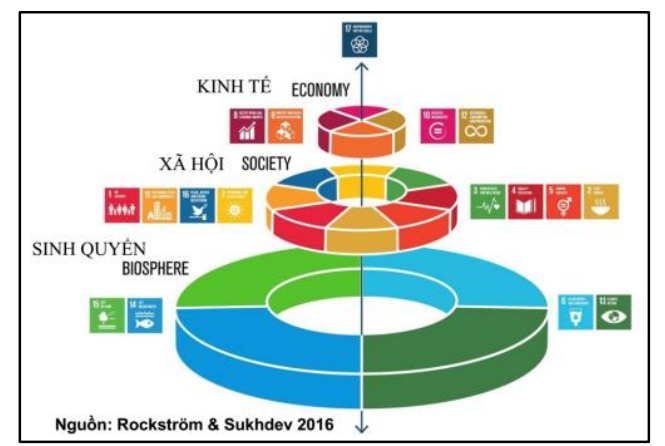

Hình 5. Các mục tiêu phát triển bền vững SDG được phân chia theo hợp phần Sinh quyển/Môi trường, Xã hội và Kinh tế. 


\subsection{Một số nỗ lự ban đầu để tích hợp phát triển bền vĩng vào chiến lược, kế hoạch và chính sách phát triển ở Việt Nam}

Việt Nam tích cực tham gia vào tiến trình thực hiện PTBV trên thế giới, đặc biệt là tham gia vào các hội nghị thượng đỉnh vào năm 1992, 2002 và 2012 đồng thời cũng đã ký kết nhiều công ước quốc tế liên quan đến bảo vệ môi trường và $\mathrm{PTBV}$. Trong quá trình thực hiện $\mathrm{PTBV}$, các nguyên tắc và mục tiêu $\mathrm{PTBV}$ quốc tế đã được cụ thể hóa phù hợp với điều kiện của Việt Nam và được tích hợp vào những chiến lược, quy hoạch và kế hoạch phát triển $\mathrm{KT}-\mathrm{XH}$ của quốc gia, cũng như của các Bộ, ngành và địa phương trong đó gắn kết và hài hòa các mục tiêu, chỉ tiêu kinh tế, xã hội, môi trường [22].

Hệ thống luật pháp của Việt Nam, đặc biệt là những luật chuyên ngành, cũng có thể phân chia một cách rất khái quát theo các trụ cột kinh tế (như luật về đất đai, năng lượng, đô thị, thuế tài nguyên), xã hội (y tế, giáo dục) và tài nguyên môi trường (luật về bảo vệ môi trường, về rừng, nước, khoáng sản, đa dạng sinh học (ĐDSH), biển và hải đảo, và phòng chống thiên tai). Định hướng chiến lược PTBV ở Việt Nam (2004) đã đặt nền tảng cho sự xây dựng và thực hiện các chiến lược ngành về kinh tế, về xã hội và về tài nguyên, môi trường và được cụ thể hóa trong Chiến lược phát triển kinh tế-xã hội giai đoạn 2001-2010 và 2011-2020, và đặc biệt là trong được Chiến lược PTBV quốc gia cho giai đoạn 2011-2020. Những lĩnh vực ưu tiên của chiến lược PTBV giai đoạn 2011-2020 đều thích hợp với 17 mục tiêu PTBV (SDG) của LHQ, và 17 mục tiêu phát triển của Việt Nam (VSDGs). Như vậy, cũng có thể nói đây là cách tiếp cận "tích hợp" các trụ cột/lĩnh vực PTBV (kinh tế, xã hội, môi trường) trong chiến lược và chính sách phát triển của Việt Nam bằng một cách có hệ thống và toàn diện. Trong thời gian sắp tới, VSDG sẽ tiếp tục được tích hợp trong Chiến lược phát triển KT-XH 2021-2030 và Kế hoạch phát triển KTXH 2021-2025 của Việt Nam [23].

\footnotetext{
${ }^{1}$ World Network of Biosphere Reserves, http://www.unesco.org/new/en/ natural-
}

Hiện nay, chưa có những hướng dẫn về tích hợp PTBV vào các chính sách phát triển kinh tếxã hội, nhưng những tài liệu hướng dẫn tích hợp chính sách khác của Việt Nam cũng có thể được xem xét, một ví dụ là Quy trình tích hợp vấn đề BĐKH vào kế hoạch phát triển kinh tế-xã hội được thực hiện theo 5 bước [24-25] và đề xuất tích hợp PTBV vào chiến lược, quy hoạch, kế hoạch (CQK) phát triển kinh tế-xã hội thông qua thực hiện "ĐMC+" hay đánh giá tác động bền vững (sustainability impact assessement - SIA) [26]. Ngoài ra, Bộ Kế hoạch và Đầu tư (2013) [27] cũng ban hành một khung hướng dẫn lựa chọn ưu tiên đầu tư thích ứng với $\mathrm{BĐKH} \mathrm{trong} \mathrm{quá} \mathrm{trình}$ lập kế hoạch phát triển KT-XH như là một quy trình tích hợp BĐKH trong công tác lập kế hoạch.

Quá trình tích hợp PTBV trong các chiến lược quy hoạch và kế hoạch phát triển kinh tế-xã hội quốc gia, ngành và địa phương có thể chia ra thành các cấp độ: (i) Cấp độ mục tiêu và lĩnh vực ưu tiên PTBV; và (ii) Cấp độ về ngành, lĩnh vực hoặc hợp phần của PTBV [28].

Tuy nhiên, hiện nay chưa có bất cứ một hướng dẫn quy trình hay nội dung tích hợp PTBV vào chính sách phát triển $\mathrm{KT}-\mathrm{XH}$ một cách đầy đủ được thể chế hóa.

\section{Khu dự trữ sinh quyển - mô hình thực hành những sáng kiến về phát triển bền vững}

\subsection{Khái niệm về khu dụ trũ̃ sinh quyển}

Khu dự trữ sinh quyển thế giới (KDTSQ) là danh hiệu của Chương trình Con người và Sinh quyển (MAB) thuộc Tổ chức Văn hóa, Khoa học và Giáo dục của Liên Hợp Quốc (UNESCO) về mô hình $\mathrm{PTBV}$, nhằm đảm bảo hài hòa giữa con người và thiên nhiên, thông qua thực hiện 3 chức năng chính là bảo tồn, phát triển và hố trợ tại 3 vùng chức năng là vùng lõi, vùng đệm và vùng chuyển tiếp. Tính đến tháng $8 / 2018$, thế giới đã có 686 KDTSQ thuộc 122 nước ${ }^{1}$, như vậy trung bình một nước có khoảng 5,6 khu.

sciences/environment/ecological-sciences/biospherereserves/world-network-wnbr/, truy cập ngày 30/8/2018. 
Từ khi hình thành vào năm 1971 cho đến nay, MAB đã xây dựng được nhiều chính sách định hướng cho tiến trình PTBV của các KDTSQ, mà quan trọng nhất là Kế hoạch hành động Madrid cho giai đoạn 2008-2013, Chiến lược MAB giai đoạn 2015-2025, Kế hoạch hành động Lima cho Chương trình MAB và Mạng lưới các KDTSQ thế giới của UNESCO (20162025). Chiến lược phát triển của MAB (20152025) đã cụ thể hóa 3 chức năng là Bảo tồn (ĐDSH, dịch vụ hệ sinh thái), Phát triển (kinh tế bền vững/kinh tế xanh), Hỗ trợ (thúc đẩy khoa học giáo dục vì sự PTBV), trong đó nhấn mạnh xây dựng mô hình PTBV, Kế hoạch hành động Lima (2016-2025) tiếp tục khẳng định việc xây dựng và củng cố các mô hình $\mathrm{PTBV}$ của KDTSQ thông qua thúc đẩy hiệu quả quản lý và đồng thời khuyến khích các quốc gia xây dựng chiến lược PTBV cho KDTSQ của mình.

Nhiều KDTSQ trên thế giới đã triển khai những hoạt động thúc đẩy hiệu quả quản lý trong thực hiện tốt các chức năng của KDTSQ. Về chức năng bảo tồn, nâng cao hiệu quả quản lý được thể hiện thông qua việc hoàn thiện thể chế cho công tác bảo tồn ĐDSH tại KDTSQ Nam Appalachian (Hoa Kỳ), hay thông qua hình thức quản lý bảo tồn có sự tham gia tại KDTSQ Sinharaja (Sri Lanka); Chức năng phát triển được thực hiện thông qua phát triển du lịch sinh thái tại KDTSQ Lac Saint-Pierre (Canađa), hoặc thông qua việc phát triển danh hiệu sản phẩm ở KDTSQ Mont Ventoux (Pháp); Thực hiện tốt chức năng hỗ trợ thông qua hoạt động giáo dục môi trường ở KDTSQ Sierra Gorda (Mêhicô) và ở KDTSQ Nord (Mađagasca), hay khuyến khích sự tham gia của cộng đồng tại KDTSQ Sinharaja (Sri Lanka) [28]. Đồng thời, hiệu quả quản lý cũng được thể hiện qua việc xây dựng được một cơ chế điều phối hiệu quả giữa các bên có liên quan của nhóm chuyên trách ở KDTSQ LacSaint Pierre (Canada), cũng như cơ chế điều phối dựa trên sự tham gia ở KDTSQ Ven biển Mũi Tây (Nam Phi), hay thông qua việc thành lập Hợp tác xã Liên hiệp Phụ nữ ở KDTSQ Arganeraie (Marôc). Hiệu quả quản lý của KDTSQ cũng phụ thuộc rất nhiều vào việc giải quyết tốt mối quan hệ giữa bảo tồn và phát triển, như việc khuyến khích áp dụng hình thức quản lý tài nguyên thiên nhiên dựa vào cộng đồng ở KDTSQ Bắc Manamara (Mađagasca), cũng như tại KDTSQ Xishuangbanna (Trung Quốc).

\section{2. Đặc điểm chung về hệ thống các khu dư trũ sinh quyển ở Việt Nam}

Việt Nam hiện nay đã có 9 KDTSQ được UNESCO thế giới công nhận, sớm nhất vào năm 2000 và gần đây nhất là 2015. Các KDTSQ có một số đặc điểm chính như sau: (1) Phân bố tương đối đồng đều ở cả 3 miền Bắc, Trung và Nam; (2) Đại diện các vùng sinh thái từ miền núi, ven biển và hải đảo; (3) Đa dạng về phân vùng, với nhiều vùng lõi; (4) Đa dạng về quản lý hành chính, với phạm vi thuộc 1 huyện, nhiều huyện hoặc nhiều tỉnh; (5) Khác biệt về quy mô không gian của KDTSQ, nhỏ nhất có diện tích 26.000 ha, đến lớn nhất là 1,3 triệu ha; (6) Đặc thù về cơ cấu tổ chức, quy chế hoạt động, cũng như đa dạng về văn hóa, dân tộc sinh sống.

Mục tiêu quản lý KDTSQ là nhằm thực hiện và phát huy tốt 3 chức năng, bao gồm: i). Bảo tồn đa dạng sinh học, bao gồm bảo tồn đa dạng hệ sinh thái và cảnh quan, đa dạng loài và đa dạng nguồn gen; ii). Thúc đẩy phát triển kinh tế bền vững về sinh thái và thân thiện với thiên nhiên, môi trường; iii). Hỗ trợ nhằm tạo điều kiện cho nghiên cứu giám sát, và giáo dục cộng đồng về bảo tồn và $\mathrm{PTBV}$.

Về quy mô không gian, các KDTSQ này cũng có diện tích rất khác nhau, từ rất nhỏ (Quần đảo Cát Bà với 26.241 ha), tới trung bình (Mũi Cà Mau - 370.321 ha), lớn (Đồng Nai - 969.993 ha) và rất lớn (Tây Nghệ $A n-1.303 .285$ ha). Theo UNESCO/MAB của CHLB Đức, để đảm bảo thực hiện quản lý hiệu quả, một KDTSQ nên có diện tích không nhỏ hơn 30.000 ha và không lớn hơn 150.000 ha [29]. Tuy nhiên, nếu so sánh với yêu cầu này thì 5 KDTSQ tại Việt Nam có diện tích lớn hơn diện tích tối đa của một KDTSQ theo tiêu chí của Đức từ khoảng 2 lần (Lang Biang, Mũi Cà Mau), đến hơn 6 lần (Đồng Nai) và khoảng 8 lần (Kiên Giang, Tây Nghệ An) và đây là một thách thức cho công tác quản lý khi nguồn lực còn hạn chế. 
Bảng 3 trình bày một số đặc điểm về diện tích và dân số của các KDTSQ ở Việt Nam. Tổng diện tích của 9 KDTSQ là hơn 4 triệu ha, chiếm khoảng $12,1 \%$ diện tích của cả nước, trong đó, vùng lõi, chủ yếu là vườn quốc gia, khu bảo tồn và rừng đặc dụng, chiếm khoảng 450.000 ha, tương đương $11 \%$ trong toàn diện tích của các khu dự trữ sinh quyển. Một vùng rộng lớn xung quanh vùng lõi, chiếm tới $89 \%$ diện tích toàn bộ các KDTSQ là vùng đệm (khoảng 1,16 triệu ha) và vùng chuyển tiếp (2,46 triệu ha), tương ứng là $28,5 \%$ và $60,5 \%$ tổng diện tích. Về mặt dân cư, có khoảng 1,78 triệu người sinh sống trong các KDTSQ, tương đương với 40 người $/ \mathrm{km}^{2}$.

Về chính sách vĩ mô, Việt Nam đã xây dựng được hệ thống chính sách khá đầy đủ về PTBV nói chung, về bảo tồn ĐDSH nói riêng, liên quan trực tiếp thực hiện các chức năng của các KDTSQ. Luật Đa dạng sinh học, Chiến lược Bảo tồn ĐDSH đến năm 2020 tầm nhìn đến năm 2030 và Quy hoạch Bảo tồn ĐDSH quốc gia đã được ban hành, đặc biệt gắn kết với bảo tồn ĐDSH và sử dụng bền vững HST, loài và nguồn gen rất phù hợp với chức năng bảo tồn và phát triển của các KDTSQ. Đây là những chính sách quan trọng có thể thúc đẩy quản lý hiệu quả tại các KDTSQ trong toàn quốc. Như vậy, điều kiện pháp lý cũng như các văn bản quy phạm pháp luật của Việt Nam đã hỗ trợ cho việc thực hiện tốt những chức năng của KDTSQ theo nguyên tắc "Bảo tồn để phát triển - Phát triển để bảo tồn" theo hướng PTBV.

Bảng 3. Một số đặc điểm về diện tích và dân số của các KDTSQ ở Việt Nam

\begin{tabular}{|l|r|r|r|r|r|r|r|}
\hline \multicolumn{1}{|c|}{ KDTSQ } & $\begin{array}{l}\text { Năm } \\
\text { công } \\
\text { nhận }\end{array}$ & \multicolumn{1}{c|}{$\begin{array}{c}\text { Vùng lõi } \\
\text { (ha) }\end{array}$} & \multicolumn{1}{c|}{$\begin{array}{c}\text { Vùng đệm } \\
\text { (ha) }\end{array}$} & \multicolumn{1}{c|}{$\begin{array}{c}\text { Vùng } \\
\text { chuyển } \\
\text { tiếp (ha) }\end{array}$} & $\begin{array}{l}\text { Tổng diện } \\
\text { tích (ha) }\end{array}$ & \multicolumn{1}{c|}{$\begin{array}{c}\text { Dân số } \\
\text { (người) }\end{array}$} & $\begin{array}{c}\text { Mật độ dân } \\
\text { số } \\
\text { (người/km²) }\end{array}$ \\
\hline $\begin{array}{l}\text { Rừng ngập mặn } \\
\text { Cần Giờ }\end{array}$ & 2000 & 4.721 & 37.339 & 29.310 & 71.370 & 56.403 & 80 \\
\hline $\begin{array}{l}\text { Quần đảo Cát } \\
\text { Bà }\end{array}$ & 2004 & 8.500 & 7.741 & 10.000 & 26.241 & 5.243 & 20 \\
\hline $\begin{array}{l}\text { Châu thổ Sông } \\
\text { Hồng }\end{array}$ & 2004 & 14.167 & 36.849 & 54.541 & 105.557 & 128.075 & 120 \\
\hline Kiên Giang & 2006 & 36.935 & 172.578 & 978.591 & 1.188 .104 & 353.893 & 30 \\
\hline Tây Nghệ An & 2007 & 191.922 & 503.270 & 608.093 & 1.303 .285 & 473.822 & 40 \\
\hline $\begin{array}{l}\text { Cù Lao Chàm- } \\
\text { Hội An }\end{array}$ & 2009 & 2.471 & 8.455 & 22.220 & 33.146 & 83.792 & 250 \\
\hline Mũi Cà Mau & 2009 & 17.329 & 43.309 & 310.868 & 371.306 & 170.321 & 50 \\
\hline Đồng Nai & 2011 & 173.073 & 349.995 & 446.925 & 969.993 & 485.900 & 50 \\
\hline Lang Biang & 2015 & 34.943 & 72.232 & 168.264 & 275.439 & 387.714 & 140 \\
\hline Tổng & & $\mathbf{4 4 9 . 1 1 8}$ & $\mathbf{1 . 1 5 9 . 5 3 6}$ & $\mathbf{2 . 4 6 0 . 5 4 8}$ & $\mathbf{4 . 0 6 9 . 0 0 2}$ & $\mathbf{1 . 7 5 7 . 4 4 9}$ & $\mathbf{4 0}$ \\
\hline
\end{tabular}

Nguồn: Võ Thanh Sơn và cs, 2018 [30].

\section{Kết luận}

Trong suốt nửa cuối thế kỷ 20 và đầu thế kỷ 21, thế giới đã chứng kiến tiến trình PTBV trên thế giới, từ nhận thức ban đầu về vai trò của môi trường trong quá trình phát triển trong những thập niên 1980s tới việc xây dựng chương trình nghị sự 21 trong thập kỷ 1990s, tới việc xây dựng và thực hiện chương trình nghị sự 2030 vì sự PTBV trong thời gian hiện tại. Sự thay đổi nhận thức và thực tiễn PTBV cũng thể hiện $x u$ thế chuyển đổi sinh thái - xã hội như là một xu thế phát triển và là một yêu cầu cấp bách nhằm hướng tới xây dựng một xã hội thịnh vượng và bền vững. Tích hợp PTBV vào các chính sách phát triển quốc tế cũng như quốc gia có thể được coi như là một hình thức thúc đẩy quá trình chuyển đổi sinh thái - xã hội. Hệ thống các KDTSQ của UNESCO như là một mô hình thúc đẩy thực hiện các sáng kiến về PTBV theo hướng 
hài hòa giữa con người và thiên nhiên có thể được coi như là một hình mẫu của một Hệ sinh thái - xã hội. Việt Nam là một quốc gia tích cực tham gia vào tiến trình $\mathrm{PTBV}$ trên thế giới và có nhiều nỗ lực nhằm xây dựng một xã hội hội thịnh vượng và bền vững.

\section{Tài liệu tham khảo}

[1] United Nations, Agenda 2, United Nations Conference on Environment \& Development Rio de Janerio, Brazil, 3 to 14 June 1992, pp. 351.

[2] IUCN, UNEP, WWF, World Conservation Strategy: Living Resource Conservation for Sustainable Development, 1980, pp. 77.

[3] United Nations, Our Common Future, Oxford: Oxford University Press, 1987.

[4] Meadows, H. Donella, Meadows, L. Dennis, Randers, Jørgen; Behrens III, W. William, The Limits to Growth; A Report for the Club of Rome's Project on the Predicament of Mankind. New York: Universe Books, 1972.

[5] IUCN, UNEP và WWF, Caring for the Earth: A Strategy for Sustainable Living (in Vietnamse), Translation from original copy, Hanoi: Science and Technology Publishing House, 1993, pp. 240.

[6] Millennium Ecosystem Assessment (MEA), Ecosystems and Human Well-being: Synthesis. Island Press, Washington, DC, 2005, pp. 102.

[7] United Nations, Global Sustainable Development Report, 2015a, pp. 198.

[8] United Nations, Transforming our world: the 2030 Agenda for Sustainable Development. A/RES/70/1, 2015b, pp. 40.

[9] Liliane Danso-Dahmen, Philip Degenhardt (Eds.), Social-Ecological Transformation Perspectives from Asia and Europe. Published by the RosaLuxemburg-Stiftung, 2019, pp. 111.

[10] Bass Steve, Conceptual Frameworks for Integrating Sustainable Development Dimensions Paper for UNDESA/UNEP/UNDP Workshop on SD Integration tools, Geneva, 14-15 October 2015.

[11] Cejudo, Guillermo M and Cynthia Michel, Addressing fragmented government action: Coordination, coherence, and integration. Paper to be presented at the 2nd International Conference in Public Policy, Milan, July 2015, pp. 22.

[12] UN-DESA, Integrated Approaches to Sustainable Development Planning and Implementation. Report of the Capacity Building Workshop and
Expert Group Meeting, Department of Economic \& Social Affairs, 2015.

[13] ESDN, Horizontal Policy Integration and Sustainable Development: Conceptual remarks and governance examples. ESDN Quarterly Report June 2009, http://www.sdnetwork.eu/quarterly\%20reports/report\%20files/p df/2009-June-

Horizontal_Policy_Integration_and_Sustainable_ Development.pdf.

[14] OECD, Guidance on Sustainability Impact Assessment. Organisation for Economic Cooperation and Development, 2010.

[15] DFID, Sustainable Livelihoods Guidance Sheets. April 1999, https://www.ennonline.net/dfidsustainableliving.

[16] Adams, W.M, The Future of Sustainability: Rethinking Environment and Development in the Twenty-first Century. Report of the IUCN Renowned Thinkers Meeting, 29-31 January 2006, pp. 18. https://portals.iucn.org/library/sites/library/files/do cuments/Rep-2006-002.pdf.

[17] J. Rockström et al., A safe operating space for humanity, Nature 461(7263), 2009a, 472-475.

[18] J. Rockström et al., Planetary Boundaries: Exploring the Safe Operating Space for Humanity. Ecology and Society 14(2), 2009b, 32.

[19] Steffen, Will, K. Richardson, J. Rockström, S.E. Cornell, I. Fetzer, E.M. Bennett, R. Biggs, S.R. Carpenter, Wim de Vries, Cynthia A. de Wit, Carl Folke, Dieter Gerten, J. Heinke, G.M. Mace, Linn M. Persson, Veerabhadran Ramanathan, B. Reyers, Sverker Sörlin, Planetary boundaries: Guiding human development on a changing planet. Science 347, 1259855 (2015). DOI: 10.1126/science. 1259855 .

[20] Pisano, Umberto and Gerald Berger, Planetary Boundaries for Sustainable Development: From a conceptual perspective to national applications. ESDN Quarterly Report 30 - October 2013, ESDN Quarterly Report N.30. European Sustainable Development Network, 31 pages, http://www.sdnetwork.eu/quarterly\%20reports/report $\% 20$ files/p df/2013-October-

Planetary_Boundaries_for_SD.pdf

[21] Raworth Kate, From Will these Sustainable Development Goals get us into the doughnut (aka a safe and just space for humanity)? Duncan Green's discussion on Raworth's doughnut and SDGs. 2014, http://oxfamblogs.org/fp2p/willthese-sustainable-development-goals-get-us-into- 
the-doughnut-aka-a-safe-and-just-space-forhumanity-guest-post-from-kate-raworth/

[22] Vietnam, Implementation of Sustainable Development: National Report at the UN Conference on Sustainable Development (Rio+20) (in Vietnamese), Ministry of Planning and Investment, Hanoi, May 2012, pp. 82.

[23] Vietnam, Voluntary National Review on the Implementation of the Sustainable Development Goals ,Ministry of Planning and Investment, 2018, pp. 90 (in Vietnamese).

[24] IMHEN, Integrating Climate Change into Socioeconomic Development Plans Viet Nam Institute of Meteorology, Hydrology and Climate Change, Viet Nam Publishing House of Natural Resources, Environment and Cartography, Hanoi, 2012, pp.137 (in Vietnamese).

[25] T. Thuc, H.T.L. Huong and D. M. Trang, Technical guidance on integrating climate change into development planning Viet Nam Institute of Meteorology, Hydrology and Climate Change, Viet Nam Publishing House of Natural Resources, Environment and Cartography, Hanoi, 2012, pp. 69 (in Vietnamese).

[26] MPI and UNDP, A study on advanced strategic environmental assessment tools for the sustainability assessment of development planning projects, A project on "Strengthening capacity to integrate sustainable development and climate change in planning in Vietnam, Hanoi, 2011, pp. 79 (in Vietnamese).

[27] Minister of the Ministry of Planning and Investment, Circular No. 02/2013/TT-BKHDT dated March 27, 2013 guiding the implementation of a number of contents of the Strategy for Sustainable Development in Vietnam for the period 2011-2020), 2013 (in Vietnamese).

[28] V.T. Son and T.T. Phuong, Monitoring and evaluation criteria for management effectiveness for biosphere reserves: Practices in the world and applicability in Vietnam (in Vietnamese). Journal of Environment, Topic II, 2018, 12-15.

[29] German MAB National Committee. Criteria for Designation and Evaluation of UNESCO Biosphere Reserves in Germany. Publisher: German National Committee for the UNESCO Programme "Man and the Biosphere" (MAB), 1996, pp. 65.

[30] V.T. Son et al, Final report of the independent State-level scientific and technological project titled "Research on developing a set of criteria and procedures for monitoring and evaluating the efficiency of management of biosphere reserves in Vietnam”, Code DTLXH, 20/15.2018. 